\author{
Research Article
}

Maryana Zagula-Yavorska*

\title{
Rhodium influence on the microstructure and oxidation behaviour of aluminide coatings deposited on pure nickel and nickel based superalloy
}

https://doi.org/10.1515/htmp-2019-0008

Received Apr 05, 2018; accepted Dec 06, 2018

\begin{abstract}
The rhodium 0,5 $\mu \mathrm{m}$ thick layer was deposited on pure nickel and CMSX $4 \mathrm{Ni}$-based superalloy using the electroplating method. The rhodium coated substrates were aluminized by the CVD method. Oxidation resistance of nonmodified and rhodium modified coatings deposited both on nickel and CMSX 4 superalloy was compared. The triple-layer structure of rhodium modified coatings deposited on pure nickel was found. The $\beta$-(Ni,Rh)Al, rhodium doped $\gamma^{\prime}-\mathrm{Ni}_{3} \mathrm{Al}$ and rhodium doped $\gamma-\mathrm{Ni}(\mathrm{Al})$ phases were the main components of the coatings on pure nickel. Two layers - additive and interdiffusion ones were identified in coatings deposited on CMSX 4 superalloy. TEM, SEM and XRD analysis revealed that $\beta$-(Ni, Rh)Al phase was the main component of the additive layer. Moreover Topologically Closed-Pack $\sigma$ phases containing refractory elements in the $\beta$-(Ni,Rh)Al matrix of the interdiffusion layer were found. The rhodium modified aluminide coatings have better oxidation resistance than the nonmodified ones both on the pure nickel and CMSX 4 superalloy.
\end{abstract}

Keywords: Nickel, rhodium, aluminide coating's formation, oxidation

\section{Introduction}

Diffusion aluminide coatings have been widely applied on turbine engine hot section blades and vane segments as protection from the aggressive conditions of industrial and aero-gas turbines [1]. This protection derives from the pro-

\footnotetext{
${ }^{\star}$ Corresponding Author: Maryana Zagula-Yavorska: Rzeszow University of Technology, Faculty of Mechanical Engineering and Aeronautics, al. Powstańców Warszawy 12, 35-959 Rzeszów, Poland; Email: yavorska@prz.edu.pl
}

motion of a slow growing $\mathrm{Al}_{2} \mathrm{O}_{3}$ oxide scale that acts as a barrier against oxidation and hot corrosion [2].

It is well known that platinum addition significantly improves resistance of aluminide coatings on high temperature oxidation and hot corrosion. It is reported that platinum is effective in reducing oxide growth stresses, enhancing $\mathrm{Al}$ concentration in the coating and suppressing void formation in the oxide scale [3]. Platinum encourages formation of pure alumina oxide and reduces oxide growth rate, moreover it acts as $\mathrm{NiAl}$ phase stabilizer and prevents the $\beta$ to $\gamma^{\prime}$ phase transformation [4]. Pint et al. [5] showed, that platinum improves the scale adhesion in cyclic oxidation test at 1150 and $1200^{\circ} \mathrm{C}$. Addition of platinum to aluminide coatings deposited by the CVD method reduced or eliminated interfacial void growth thereby improving contact between metal and scale [6]. According to Schneider et al. [7] superalloys coated by platinum modified aluminide coatings have poor high cyclic fatigue performance. Therefore, it is necessary to replace platinum in aluminide coatings by other metals. Literature data indicate that small amounts of reactive elements (zirconium, hafnium, yttrium or cerium) in the aluminide coatings improves their oxidation resistance [8]. Zirconium migrates via $\beta$-NiAl grain boundaries towards the surface during oxidation and distributes homogeneous in the whole oxide scale. Zirconium delays oxide spalling during oxidation of coatings, inhibits also the formation of cavities at the $\beta$-NiAl/oxide scale interface. Zirconium locates in the sub-lattice of NiAl, contributes to faster annihilation of aluminum vacancies and to their fast diffusion toward the metal/oxide interface and inhibits the cavities formation and growth. The absence of cavities improves thermally grown alumina scale adhesion on the $\beta$-NiAl phase coating. Hafnium addition to the aluminide coatings increases oxide scale adhesion to the coating and decreases scale growth rate during oxidation [9]. According to Li et al. [10] hafnium ions first segregate to the scale/coating interface during oxidation. Then diffuse to the oxide scale surface

๖ Open Access. (c) 2019 M. Zagula-Yavorska, published by De Gruyter. (Cc) BY 4.0 License 
Table 1: Chemical composition of the CMSX 4 superalloy, \% wt.

\begin{tabular}{ccccccccccc}
\hline $\mathrm{Ni}$ & $\mathrm{Cr}$ & $\mathrm{Mo}$ & $\mathrm{Nb}$ & $\mathrm{Ta}$ & $\mathrm{Al}$ & $\mathrm{Ti}$ & $\mathrm{Co}$ & $\mathrm{W}$ & $\mathrm{Hf}$ & $\mathrm{Re}$ \\
\hline 61.7 & 6.5 & 0.6 & - & 6.5 & 5.6 & 1 & 9 & 6 & 0.1 & 3 \\
\hline
\end{tabular}

along oxide grain boundaries. The slow outward diffusion of large hafnium ions stands against the outward diffusion of aluminum ions and inward diffusion of oxygen. Thus the alumina scale growth rate decreases. In spite of the beneficial effect of reactive elements on aluminide coatings' oxidation resistance, there are some difficulties to incorporate small amount of reactive elements to aluminide coatings.

Improvement of the aluminide coated superalloys oxidation resistance might be achieved by modifying of coated superalloys with other elements. Oxidation resistance of the Ni-8Cr-6Al alloy with $5 \mathrm{wt} . \%$ of rhodium was investigated by Felten [11]. The addition of $5 \mathrm{wt} . \%$ rhodium to the $\mathrm{Ni}-8 \mathrm{Cr}-6 \mathrm{Al}$ alloy is approximately equivalent to 10 wt. $\%$ of platinum. Such small amount of rhodium in the $\mathrm{Ni}-8 \mathrm{Cr}-6 \mathrm{Al}$ alloy increases oxide scale adherence to the alloy and improves its oxidation resistance. Rhodium addition to the aluminide coating also improves oxidation resistance of the coated superalloy [12].

In spite of good oxidation resistance of the rhodium modified aluminide coating, mechanism of its formation is unknown. Therefore in this paper, the influence of rhodium on the microstructure and phase composition of aluminide diffusion coatings deposited on the nickel substate and CMSX 4 Ni-based superalloy by the CVD metod is analysed. The explanation of mechanism of the rhodium modified aluminide coating formation on pure nickel and CMSX 4 Ni-based superalloy was attempted. Oxidation behaviour of rhodium modified aluminide coatings and nonmodified one on pure nickel and CMSX $4 \mathrm{Ni}$-based superalloy was compared.

\section{Experimental procedure}

The commercial nickel of $99.95 \mathrm{wt} \%$ purity and CMSX $4 \mathrm{su}-$ peralloy (monocrystal) were cut and grounded up to SiC No 1000, degreased in ethanol, ultrasonically cleaned and finally coated by the rhodium layer $(0.5 \mu \mathrm{m}$ thick). The chemical composition of the CMSX 4 superalloy is presented in Table 1. The rhodium layer was deposited by the electroplating method. Rhodium electroplating process was conducted in the bath of rhodium sulphate $\mathrm{Rh}_{2}\left(\mathrm{SO}_{4}\right)_{3}$ $-0.1 \mathrm{~g} / \mathrm{dm}^{3}$, sulphuric acid $\mathrm{H}_{2} \mathrm{SO}_{4}-0.15 \mathrm{~g} / \mathrm{dm}^{3}$ and sele- nium acid $\mathrm{H}_{2} \mathrm{SeO}_{4}-0.010 \mathrm{~g} / \mathrm{dm}^{3}$ at $50^{\circ} \mathrm{C}$. The current density during the electroplating process was about $0.2 \mathrm{~A} / \mathrm{dm}^{2}$. The samples were cleaned in water heated to $70^{\circ} \mathrm{C}$ after electroplating process [13].

Afterwards, aluminide coatings were deposited in the low activity CVD process using the CVD BPXPR0325S equipment manufactured by the IonBond company [1315].

The microstructure of the cross-sections of the coatings were investigated by the optical microscope Nikon Epiphot 300, the scanning electron microscope (SEM) Hitachi S-3400N and energy dispersive spectroscope (EDS). Phase composition of the nonmodified and rhodium modified aluminide coatings was investigated using ARL X'TRA X-ray diffractometer, equipped with a filtered copper lamp with a voltage of $45 \mathrm{kV}$. The rhodium modified as well as nonmodified aluminide coatings on the pure nickel and CMSX 4 Ni-based superalloy were oxidized in the air atmosphere at $1100^{\circ} \mathrm{C}$. Samples were placed in the furnace heated to $1100^{\circ} \mathrm{C}$, removed from the furnace after $20 \mathrm{~h}$ and cooled in the air atmosphere to the room temperature. Specimens were weighed after each cycle of oxidation.

\section{Results}

\subsection{Rhodium modified aluminide coatings deposited on pure nickel}

SEM investigation and EDS analysis of rhodium modified aluminide coatings on pure nickel revealed their triplelayer structure (Figure 1, Table 2). In the first layer, on the top of the coating, the proportion of $\mathrm{Ni}$ to Al corresponds to the $\beta$-NiAl phase (Table 2, point 1-2). Rhodium

Table 2: EDS results of the spots of Figure 1 in at.\%.

\begin{tabular}{cccc}
\hline Spot & $\mathrm{Al}$ & $\mathrm{Ni}$ & $\mathrm{Rh}$ \\
\hline 1 & 39.6 & 60.4 & $<0.1$ \\
2 & 37.9 & 62.1 & $<0.1$ \\
3 & 35.1 & 63.5 & 1.4 \\
4 & 23.1 & 76.8 & 0.1 \\
5 & 12.9 & 87.1 & 0.1 \\
6 & - & 100 & - \\
\hline
\end{tabular}




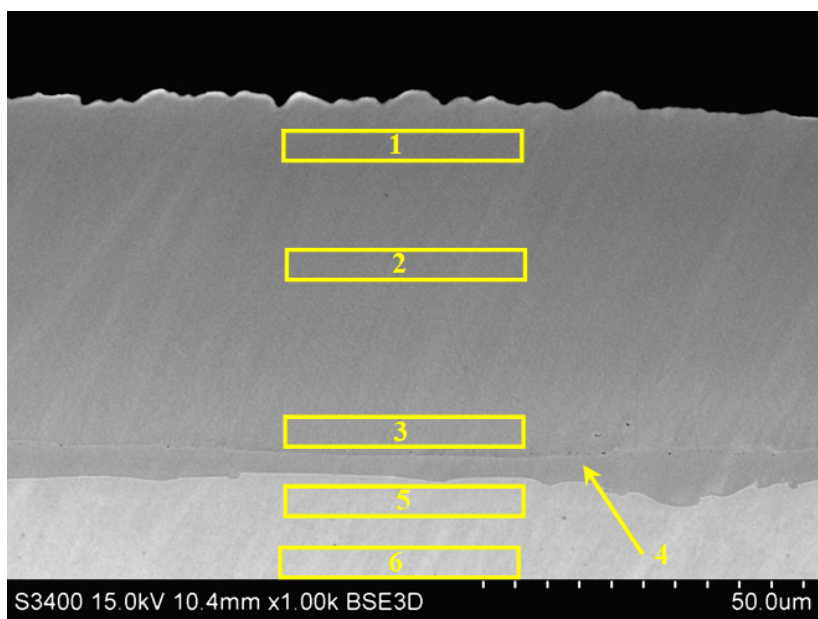

Figure 1: Microstructure on the cross-section of the rhodium modified aluminide coating deposited on pure nickel.

content is low $(<0.1$ at.\%). Therefore, it may be assumed that rhodium doped $\beta$-NiAl phase is being formed. The thickness of the top-layer is about $55 \mu \mathrm{m}$. The second layer, below is thinner (about 5-10 $\mu \mathrm{m}$ ) and consists of the $\gamma^{\prime}$. $\mathrm{Ni}_{3} \mathrm{Al}$ phase (Table 2, point 4). Rhodium content in the $\gamma^{\prime}$. $\mathrm{Ni}_{3} \mathrm{Al}$ phase is $<0.1$ at.\%. It suggests that rhodium doped $\gamma^{\prime}-\mathrm{Ni}_{3} \mathrm{Al}$ phase is being formed. The chemical composition of the third, inner layer, corresponds to the rhodium doped $\gamma-\mathrm{Ni}(\mathrm{Al})$ phase, i.e. the rhodium doped aluminum solid solution in nickel (Table 2, point 5). Chemical composition of the zone below rhodium doped $\gamma-\mathrm{Ni}(\mathrm{Al})$ phase is the same as the matrix composition, that is pure nickel (Table 2, point 6). Rhodium content between the first and second layer is about 1.4 at.\%. (Table 2, point 3). Therefore the $\beta$ - $(\mathrm{Ni}, \mathrm{Rh}) \mathrm{Al}$ phase is being formed between the first and second layers. The EDS analysis of the cross-section of the rhodium modified aluminide coating (Figure 2) suggests nickel outward diffusion from the substrate and aluminum inward diffusion from the surface. The decrease of aluminum content and increase of nickel content from the surface to the material substrate is typical for the lowactivity aluminizing process [14]. EDS cross-section results confirmed that the largest rhodium content (1.4 at.\%) is between the first and the second layer. The XRD surface analysis revealed that peaks of the $\beta$-NiAl phase in the rhodium modified coating are shifted to bigger diffraction angles in comparison to the $\beta$-NiAl phase peaks of the nonmodified coating (Figure 3). This is probably due to the incorporation of rhodium to the $\beta$-NiAl phase. Rhodium modified aluminide coating deposited on pure nickel has better oxidation resistance than nonmodified ones (Figure 4). The weight loss of the nonmodified coatings is about -18 $\mathrm{mg} / \mathrm{cm}^{2}$ just after four cycles of oxidation, while for the

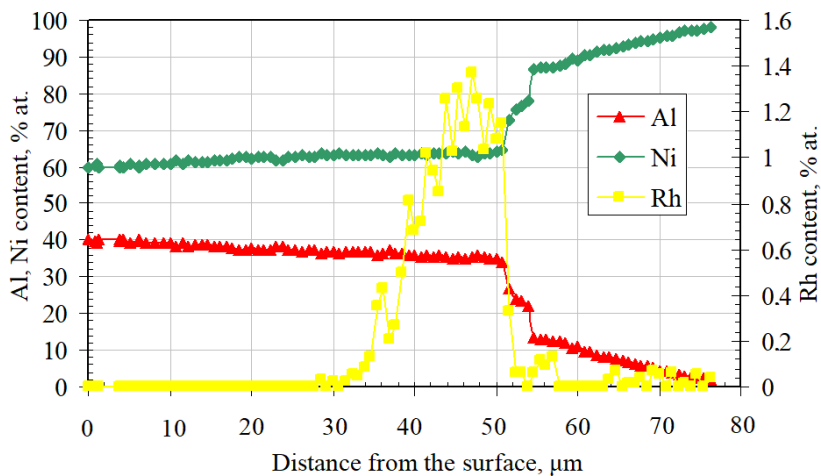

Figure 2: EDS analysis on the cross-section of the rhodium modified aluminide coating deposited on pure nickel.

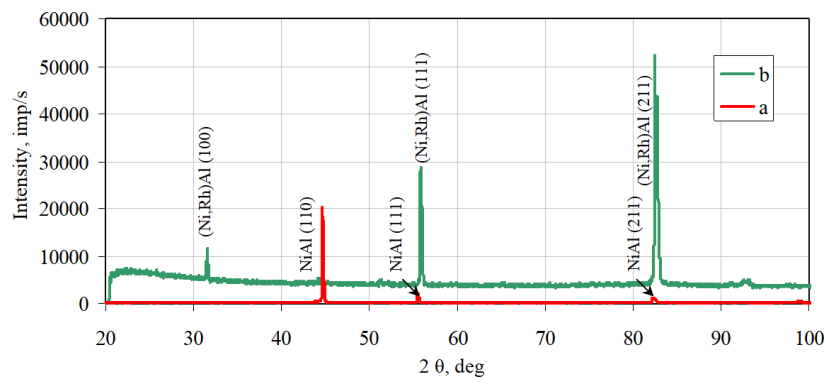

Figure 3: X-ray diffraction of the nonmodified (a) and rhodium modified (b) aluminide coating deposited on pure nickel.

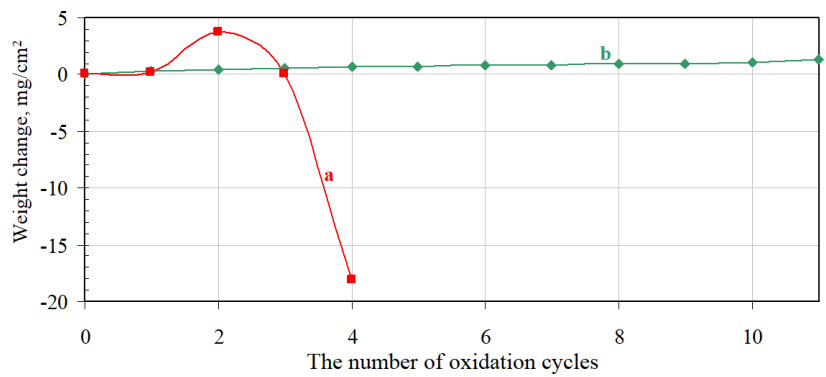

Figure 4: Oxidation test results of the nonmodified (a) and rhodium modified (b) aluminide coating deposited on pure nickel.

rhodium modified coatings the wieght chage is about +1 $\mathrm{mg} / \mathrm{cm}^{2}$ after 11 cycles of oxidation (Figure 4).

\subsection{Rhodium modified aluminide coatings deposited on CMSX 4 Ni-based superalloy}

The SEM investigation and the EDS analysis of the rhodium modified aluminide coating on CMSX 4 superalloy revealed the double layer (additive and interdiffusion) structure (Figure 5). In the first additive layer, on the top of the coating, the proportion of $\mathrm{Ni}$ do $\mathrm{Al}$ corresponds to the $\beta$ - 
Table 3: EDS results of the spots of Figure 5 in at.\%.

\begin{tabular}{cccccc}
\hline Spot & $\mathrm{Al}$ & $\mathrm{Cr}$ & $\mathrm{Ni}$ & $\mathrm{Rh}$ & $\mathrm{Re}$ \\
\hline $\begin{array}{c}\text { Additive layer } \\
\begin{array}{c}\text { Additive/Interdiffusion } \\
\text { layer }\end{array}\end{array}$ & 43.7 & 2.6 & 53.1 & 0.3 & 0.3 \\
$\begin{array}{c}\text { Interdiffusion layer } \\
\text { Inter }\end{array}$ & 36.2 & 7.3 & 52.0 & 3.2 & 0.4 \\
\hline
\end{tabular}

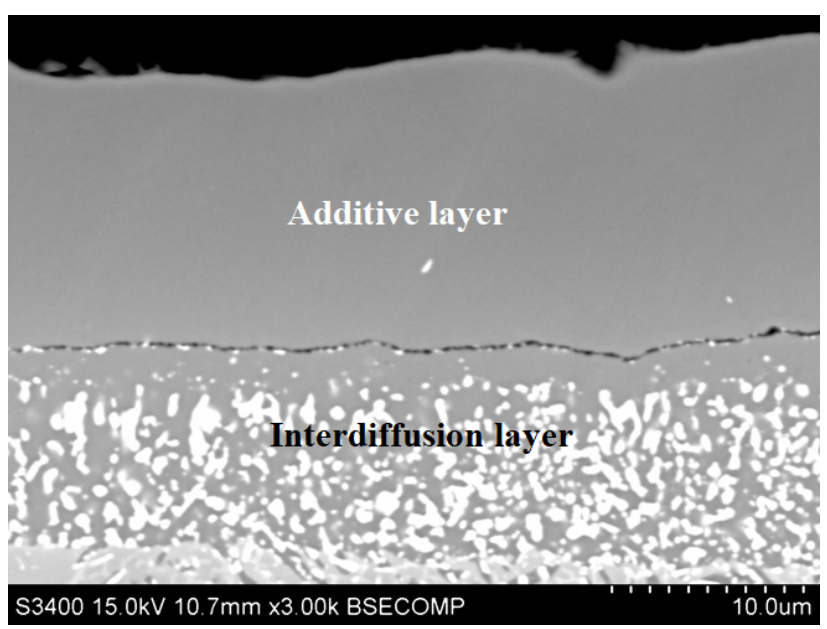

Figure 5: Microstructure on the cross-section of the rhodium modified aluminide coating deposited on CMSX 4 Ni-based superalloy.

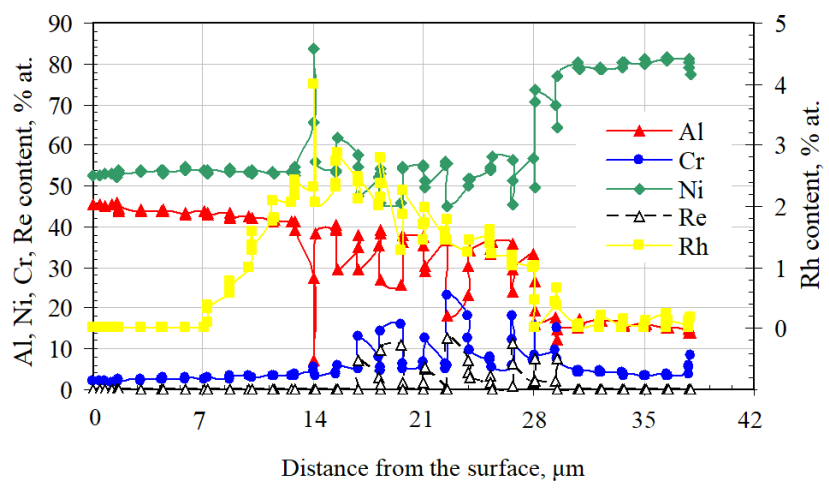

Figure 6: EDS analysis on the cross-section of the rhodium modified aluminide coating deposited on CMSX $4 \mathrm{Ni}$-based superalloy [13].

NiAl phase (Table 3, point 1). Small rhodium (0.3 at.\%) content was also identified. Such chemical composition indicates that the rhodium doped $\beta$-NiAl phase in the additive layer is being formed. The thickness of the additive layer is about $15 \mu \mathrm{m}$. The EDS analysis on the cross-section confirms the presence of the $\beta$-NiAl phase in the interdiffusion layer (Figure 6). The largest (3.2 at.\%) rhodium content between the additive and interdiffusion layer was identified. No rhodium-rich particles were observed, so rhodium incorporates into the $\beta$-NiAl phase. Rhodium content in the interdiffusion layer is about 2.7 at.\%. Therefore it may

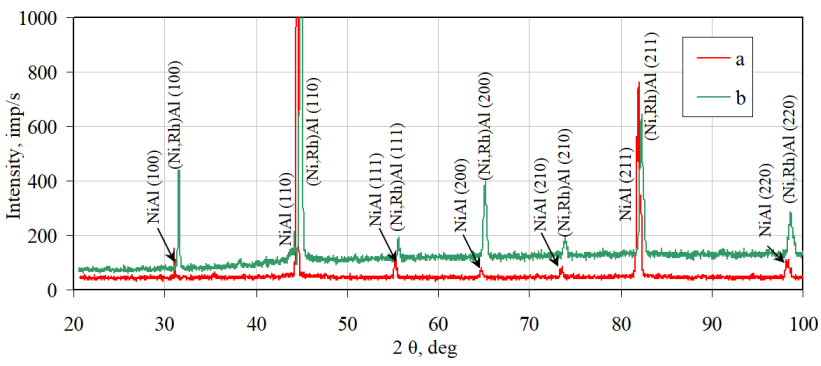

Figure 7: X-ray diffraction of the nonmodified (a) and rhodium modified (b) aluminide coating deposited on CMSX $4 \mathrm{Ni}$-based superalloy.
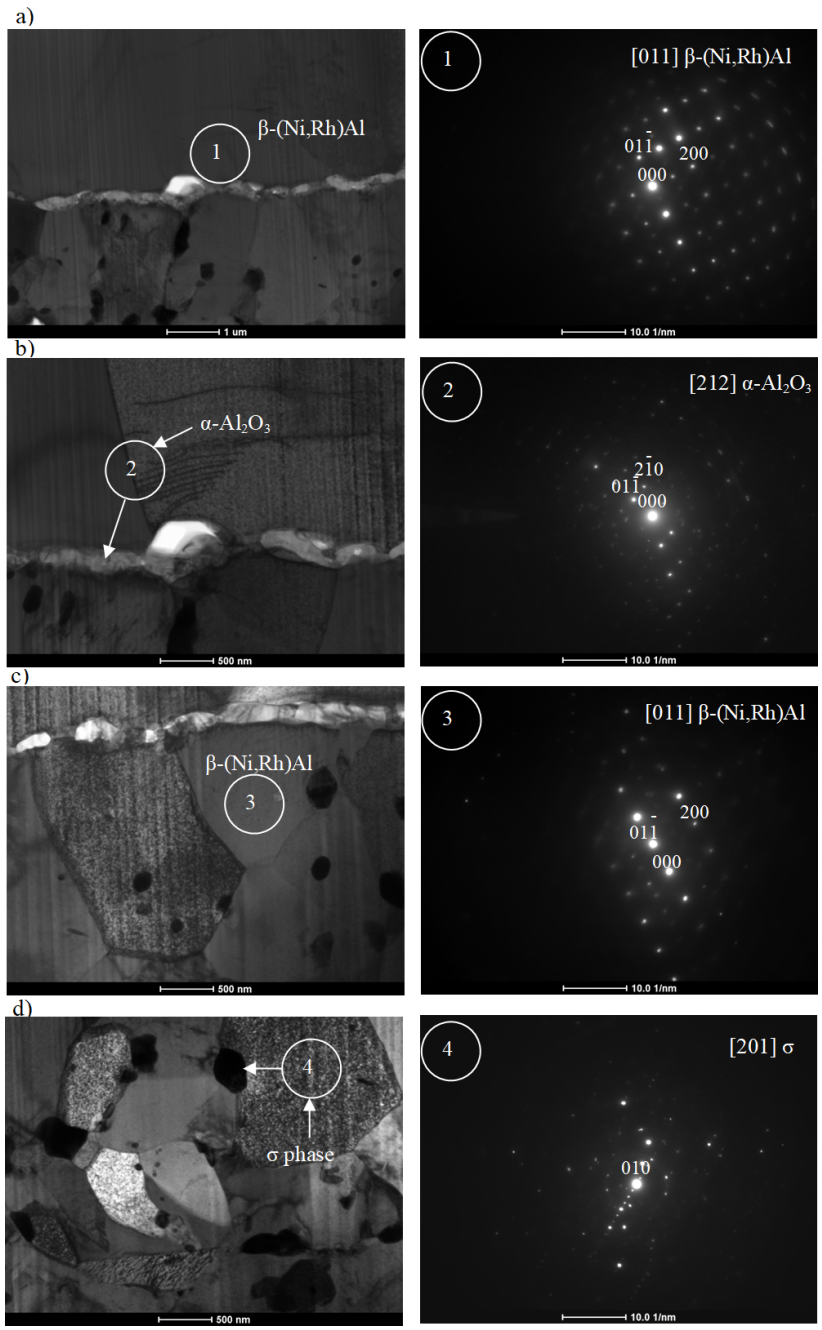

Figure 8: TEM image and SAED patterns of the cross-section of the rhodium modified aluminide coating on CMSX 4 superalloy: additive layer (a), additive/interdiffusion layer (b) and interdiffusion layer (c-d) [15].

be assumed that rhodium modified $\beta$-NiAl phase is being formed. The thickness of the interdiffusion layer is about 15 $\mu \mathrm{m}$. The XRD surface analysis revealed that peaks of the $\beta$ NiAl phase of the rhodium modified coating are shifted to 

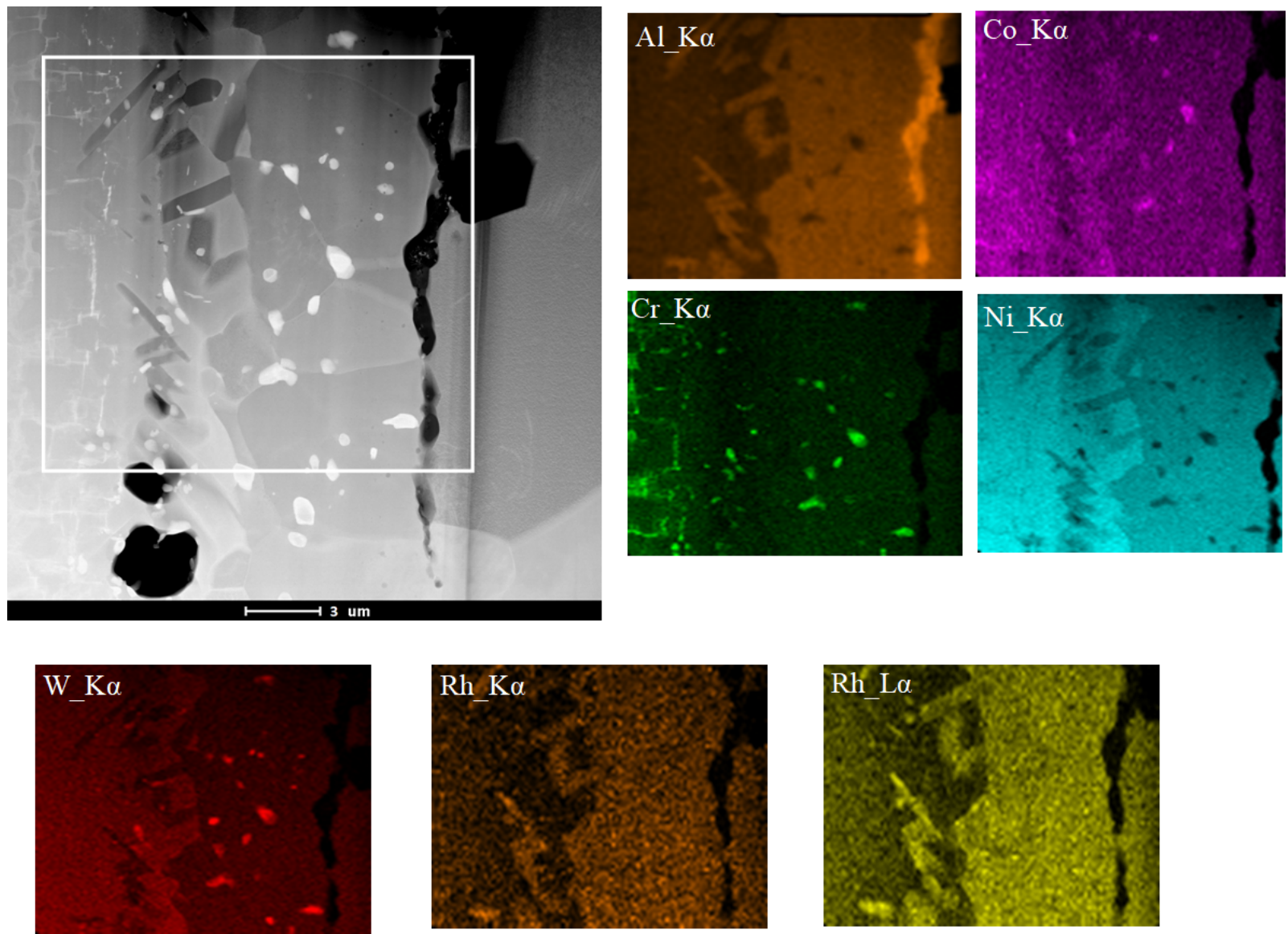

Figure 9: STEM HAADF image of the cross-section of the rhodium modified aluminide coating on CMSX 4 superalloy with corresponding maps of Al, Co, Cr, Ni, W and Rh [15].

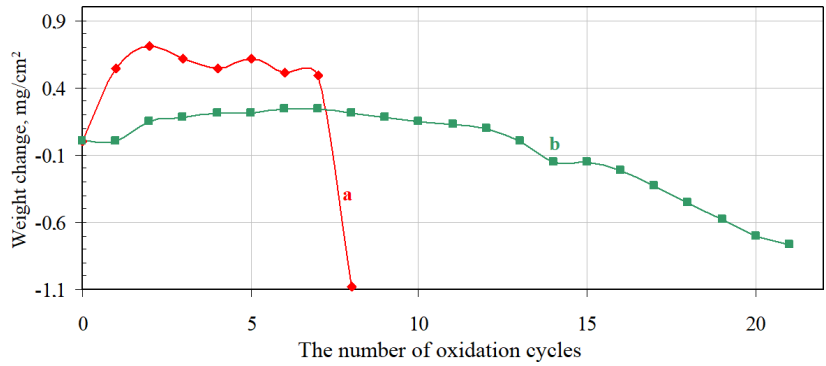

Figure 10: Oxidation test results of the nonmodified (a) and rhodium modified (b) aluminide coating deposited on CMSX $4 \mathrm{Ni}$-based superalloy.

bigger diffraction angles in comparison to the $\beta$-NiAl phase peaks of the nonmodified coating (Figure 7). This is probably due to incorporation of rhodium to the $\beta$-NiAl phase.

TEM investigations of the cross-section also showed a double layers structure of rhodium modified aluminide coatings. $\beta$-(Ni, Rh)Al phase was identified in the additive layer (Figure 8a). Moreover $\alpha-\mathrm{Al}_{2} \mathrm{O}_{3}$ oxide was formed at the interface of additive/interdiffusion layer (Figure $8 \mathrm{~b}$ ).
The grains of $\beta$-(Ni,Rh)Al phase were revealed in the interdiffusion layer (Figure 8b). Numerous inclusions of $\sigma$ phase containing tungsten, chromium and cobalt in the interdiffusion layer were found (Figure 8c-9). The maps of chemical composition revealed uniform distribution of nickel and aluminum both in the additive and interdiffusion layers. Such distribution confirms the same phase composition of both layers (Figure 9). Rhodium was found only in the $\beta$-NiAl phase. This indicates, that it dissolves in the coating (Figure 9).

Weight loss of the nonmodified coatings is about -1.1 $\mathrm{mg} / \mathrm{cm}^{2}$ just after eight cycles of oxidation, while wieght loss to about $-0.8 \mathrm{mg} / \mathrm{cm}^{2}$ in the rhodium modified coatings falls down after 21 cycles of oxidation (Figure 10).

\section{Discussion}

The EDS analysis on the crosss-section of the rhodium modified aluminide coating on pure nickel showed outward nickel diffusion from the substrate and the inward 
aluminum diffusion from the surface to the nickel substrate (Figure 2). XRD surface analysis of the rhodium modified aluminide coating on pure nickel confirmed that rhodium was successively introduced to the coating (Figure 3). No rhodium-rich parties were observed, so rhodium is dissolved in the coating. Rhodium modification of aluminide coating improves oxidation resistance of coated nickel (Figure 4).

Mechanism of nonmodified aluminide coating formation on pure nickel was proposed by Gowad and Boone [16]. It was found, that nickel prefentially diffuses outward and combines with aluminum to form $\beta$-NiAl phase during low activity aluminizing of pure nickel.

During the aluminizing process of rhodium coated nickel substrate, rhodium probably dissolves in the nickel substrate, whereas nickel preferentially diffuses out from the substrate and combines with aluminum to form rhodium doped $\beta$-NiAl, $\gamma^{\prime}-\mathrm{Ni}_{3} \mathrm{Al}$ and $\gamma$-Ni(Al) phases (Figure 11). According to Wang et al. [17] enthalpy of the $\beta$-NiAl phase formation at $1000^{\circ} \mathrm{C}$ is about $-67 \mathrm{~kJ} / \mathrm{mol}$, while enthalpy of the $\gamma^{\prime}-\mathrm{Ni}_{3} \mathrm{Al}$ phases formation is $-42 \mathrm{~kJ} / \mathrm{mol}$. So it may be assumed that rhodium doped $\beta$-NiAl phase forms earlier than rhodium doped $\gamma^{\prime}-\mathrm{Ni}_{3} \mathrm{Al}$ phase. The coating grows outward. The largest rhodium content (about 1.4 at.\%) between the first and second zones in the $\beta$-NiAl phase provides $\beta$-(Ni,Rh)Al phase formation.

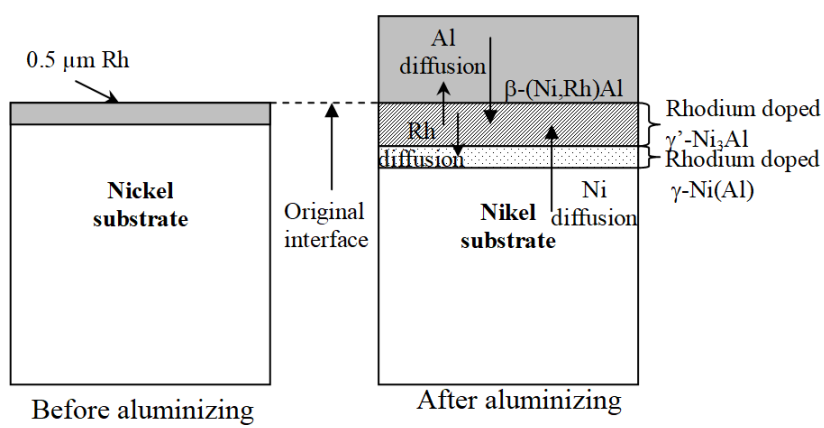

Figure 11: Rhodium modified aluminide coating formation on pure nickel.

The XRD surface analysis of the rhodium modified aluminide coating on CMSX 4 superalloy confirmed that rhodium was successively introduced to the coating (Figure 7). No rhodium-rich parties were observed. The rhodium content between the additive and interdiffusion layers is $3-4$ at.\%. According to the $\mathrm{Al}-\mathrm{Ni}-\mathrm{Rh}$ phase diagram, this is too low to form rhodium-rich precipitations [18]. So rhodium is dissolved in the coating.

Formation of the rhodium-modified aluminide coating on CMSX 4 superalloy takes place in several steps: firstly rhodium probably dissolves in $\gamma+\gamma^{\prime}$ phases near the surface of CMSX 4 superalloy; secondly nickel, chromium, rhenium and other superalloys' elements diffuses from the substrate to the surface, leading to formation of the interdiffusion layer; thirdly aluminum - during aluminizing in the CVD process arrives at the surface. Since aluminum has more affinity to nickel than rhodium, it forms the $(\mathrm{Ni}, \mathrm{Rh}) \mathrm{Al}$ phase layer, similarly to the case of the platinummodified aluminide coating [19] (Figure 12).

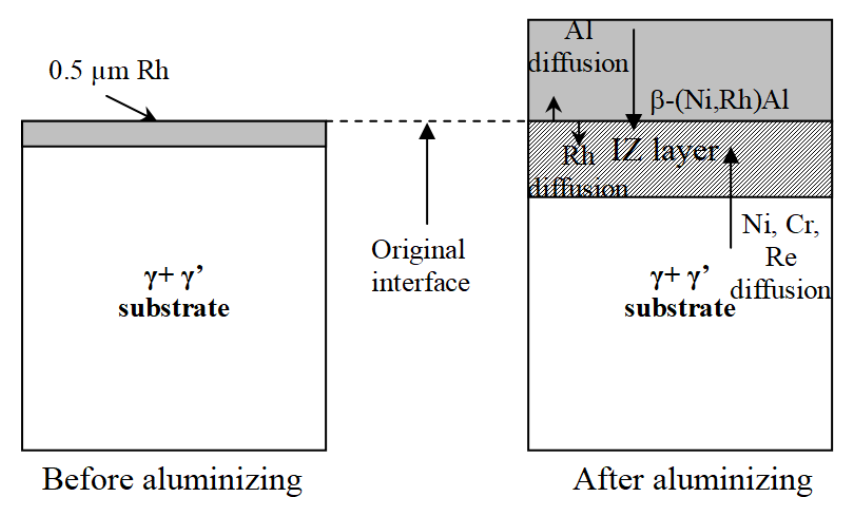

Figure 12: Rhodium modified aluminide coating formation on CMSX $4 \mathrm{Ni}$-based superalloy.

A small rhodium content in aluminide coatings (3-4 at.\%) improves oxidation resistance of CMSX 4 superalloy. Moreover rhodium modified aluminide coating deposited on CMSX 4 Ni-based superalloy has better oxidation resistance than the nonmodified one.

\section{Conclusions}

Rhodium modified aluminide coatings were successfully deposited on pure nickel and CMSX-4 nickel superalloy. Coatings deposited on pure nickel have triple-layer structure. The top layer of coatings consists of the $\beta$-(Ni,Rh)Al phase, whereas the second layer consists of the rhodium doped $\gamma^{\prime}-\mathrm{Ni}_{3} \mathrm{Al}$ phase. The rhodium doped $\gamma$-Ni(Al) phase of the third layer of the coating was identified. While coatings deposited on CMSX 4 Ni-base superalloy consist of two layers - additive and interdiffusion ones. TEM, SEM and XRD analysis proved that rhodium incorporates into the $\beta$-NiAl phase and the $\beta$-(Ni,Rh)Al phase is being formed in the additive layer. Topologically Closed-Pack $\sigma$ phases containing refractory elements distribute in the $\beta$ $(\mathrm{Ni}, \mathrm{Rh}) \mathrm{Al}$ matrix of the interdiffusion layer. Small rhodium addition to the aluminide coating improves oxidation resistance of both pure nickel and CMSX $4 \mathrm{Ni}$-based superalloy. 
Acknowledgement: This research was supported by the National Science Centre, Poland (NCN), project number 2016/21/D/ST8/01684.

\section{References}

[1] Y. Tamarin, Protective Coatings for Turbine Blades, AMS International, Materials Park, (2002).

[2] G.W. Goward, Materials Science and Technology, 2 (1986) 194200.

[3] Y. Zhang, J. A. Haynes, W. Lee, I.G. Wright, B. A. Pint, K. M. Cooley, and P. K. Liaw, Metall. Mater. Trans. A, 32 (2001) 1727-1741.

[4] M. Zagula-Yavorska and J. Sieniawski. Journal of Materials Engineering and Performance, 23 (2014) 918-926.

[5] B.A. Pint, I.G. Wright, W.Y. Lee, Y. Zhang, K. Prüßner, and K.B. Alexander, Materials Science and Engineering A, 245 (1998) 201211.

[6] B.A. Pint and I.G. Wright, Electrochem Soc. Proc., 98-99 (1998) 263-274.

[7] K. Schneider, H. Arnim, and H. Grünling, Thin Solid Films, 84 (1981) 29-36.
[8] B. Pint, T. Haynes, and T. Besmann, Surf. Coat. Technol., 205 (2010) 3287-3293.

[9] J. Haynes, B. Pint, K. More, and Y. Zhang, Oxidation of metals, 58 (2002) 513-544.

[10] D. Li, H. Guo, D. Wang, T. Zhang, S. Gong, and X. Hubin, Corros. Sci., 66 (2013) 125-135.

[11] E. Felten, Oxid. Met., 10 (1976) 23-28.

[12] M. Zagula-Yavorska, M. Wierzbińska, K. Gancarczyk, and J. Sieniawski, Journal of Microscopy, 23 (2016) 118-123.

[13] M. Zagula-Yavorska, M. Wierzbińska, and J. Sieniawski, Metals, 7 (2017) 548.

[14] J. Romanowska, M. Zagula-Yavorska, and J. Sieniawski, Bull. Mater. Sci., 36(6) (2013) 1043-1048.

[15] M. Zagula-Yavorska, J. Morgiel, J. Romanowska, and J. Sieniawski, Journal of Microscopy, 261(3) (2016) 320-345.

[16] G. Goward and D. Bone, Oxidation of Metals, 3 (1971) 475-495.

[17] Y. Wang, Z. Liu, and L. Chen, Acta Materialia, 52 (2004) 26652671.

[18] B. Przepiórzyński, S. Mi, B. Grushko, and M. Surowiec, Intermetallics, 15 (2007) 918-928.

[19] J. Benoist, K. Badawi, A. Malie, C. Ramade, Surf. Coat. Technol., $182(2004) 14$. 